\title{
Prevalência e etiologia da mastite bovina na região de Nova Tebas, Paraná
}

\author{
Prevalence and etiology of bovine mastitis in the Nova Tebas, \\ Parana
}

\author{
Andreia Bittar Saab ${ }^{1}$; Thiago Oliveira Zamprogna ${ }^{2}$; Thays Mizuki Lucas²; \\ Kelli Cristina Martini²; Priscila Luiza Mello; ${ }^{1}$ Aristeu Vieira da Silva ${ }^{3}$; \\ Lisiane Almeida Martins ${ }^{4 *}$
}

\section{Resumo}

\begin{abstract}
A mastite é a infecção mais frequente dos animais destinados à produção de leite e que mais onera a pecuária leiteira. As perdas econômicas são causadas tanto pelos honorários profissionais, medicamentos, morte ou descarte precoce de animais, bem como em laticínios, pela queda na qualidade do produto final e diminuição no rendimento industrial para a fabricação dos seus derivados e pelas alterações na composição do leite mastítico. Considerando a relevância desta enfermidade, este estudo teve como objetivo verificar a prevalência e etiologia de mastite na região de Nova Tebas - PR, analisando 336 vacas em lactação de 17 propriedades, totalizando 1324 quartos mamários através do CMT, CCS e isolamento bacteriano. Verificou-se 1120 quartos mamários (84,6\%) negativos no teste de CMT e $204(15,4 \%)$ positivos. Dentre os quartos positivos, $155(75,9 \%)$ apresentaram crescimento bacteriano, verificando a maior prevalência Staphylococcus coagulase negativa - SCN 51 (32,9\%), Streptococcus sp. 49 (31,6\%), Corynebacterium bovis 19 (12,3\%), Staphylococcus coagulase positiva - SCP 19 (12,3\%), bacilo Gram negativo (BGN) 12 (7,7\%), Corynebacterium sp. 3 (1,9\%), e Candida sp. 2 (1,2\%). Os resultados encontrados neste trabalho mostram que a prevalência de mastite na região de Nova Tebas é compatível aos encontrados nas demais regiões do Brasil, bem como os agentes etiológicos mais frequentes.

Palavras-chave: Glândula mamária, infecção, diagnóstico, California Mastitis Test, contagem de células somáticas
\end{abstract}

\begin{abstract}
Mastitis is an infection which often commits animals assigned for milk production. It has been the major price raise factor for dairy cattle breeding. Economical losses impact on professional fees, drugs, death and early discard of the animal as well as dairy companies as a result of the downturn in product end-quality, decrease of industrial procedure regarding dairy product manufacturing and changes in mastitic milk composition. Considering the relevance of such disease, this study verifies mastitis prevalence and etiology in the region of Nova Tebas, $P R$ by analyzing 336 lactating dairy cows from 17 farms, totalizing 1324 mammary quarters through CMT, SCS and bacterial isolation. Negative (1120 mammary quarters $-84.6 \%)$ and positive $(204$ mammary quarters $-15.4 \%)$ results for CMT were

\footnotetext{
${ }^{1}$ Discentes de Mestrado em Ciência Animal, Universidade Paranaense, UNIPAR, Umuarama, PR. E-mail: andreia.saab@bol.com. br; priscila_mello@msn.com

${ }^{2}$ Discentes de Medicina Veterinária, UNIPAR, Umuarama, PR. E-mail: tzamprogna@gmail.com; thaysmizuki@yahoo.com.br; kellivet@hotmail.com

${ }^{3}$ Prof. da Universidade Estadual de feira de Santana, UEFS, Feira de Santana, BA. E-mail: aristeuvsilva@uefs.br

${ }^{4}$ Prof ${ }^{a}$ de Medicina Veterinária e Mestrado em Ciência Animal, UNIPAR, Umuarama, PR. E-mail: lisiane.almeida.martins@gmail.com

* Autor para correspondência
} 
verified. Among the positive quarters, $155(75.9 \%)$ presented bacterial growth - higher prevalence of coagulase-negative Staphylococcus - SCN 51 (32.9\%), Streptococcus sp. 49 (31.6\%); Corynebacterium bovis 19 (12.3\%), coagulase-positive Staphylococcus - SCP 19 (12.3\%), Gram-negative bacilli (BGN) $12(7.7 \%)$, Corynebacterium sp. 3 (1.9\%), and Candida sp. 2 (1.2\%). Results show that mastitis in the region of Nova Tebas is compatible to those found all over Brazil together with the highest prevalent etiological agents. Such profile of animals with mastitis can be noticed from screening tests used for mastitis such as CMT and SCS.

Key words: Mammary gland, infection, diagnosis, California Mastitis Test, somatic cell count

\section{Introdução}

A atividade leiteira desempenha importante função social com a fixação de milhares de famílias no meio rural. No entanto, como em muitas regiões do país, a bovinocultura de leite no Estado do Paraná apresenta problemas relacionados à sazonalidade forrageira, ao balanceamento da dieta alimentar, ao melhoramento genético, à sanidade do rebanho, à qualidade do leite, à assistência técnica, à industrialização e à comercialização dos produtos (FAGAN, 2006).

O sistema agro-industrial do leite, devido a sua enorme importância social, é um dos mais importantes do país. A qualidade do leite in natura é influenciada por muitas variáveis, entre as quais se destacam fatores zootécnicos associados ao manejo, alimentação, potencial genético dos rebanhos e fatores relacionados à obtenção e armazenagem do leite. Uma das causas que exerce influência extremamente prejudicial sobre a composição e as características físico-químicas do leite é a mastite, acompanhada por um aumento na contagem de células somáticas no leite (MULLER, 2002).

A mastite é a infecção mais frequente dos animais destinados à produção de leite, e que mais onera a pecuária leiteira. As perdas econômicas são causadas tanto pelos honorários profissionais, medicamentos, morte ou descarte precoce de animais, bem como na produtividade dos laticínios, pela queda na qualidade do produto final e diminuição no rendimento industrial para a fabricação dos seus derivados e pelas alterações na composição do leite mastitico (LANGONI, 1999).
O termo mastite refere-se à inflamação da glândula mamária, qualquer que seja a causa. Caracteriza-se por alterações físicas, químicas e, em geral, bacteriológicas do leite e por alterações patológicas do tecido glandular (BLOOD; RADOSTITS, 1991), podendo ser classificada como clínica e subclínica, sendo que a forma subclínica é muito mais frequente.

As mastites podem ser classificadas, de acordo com o agente etiológico, em ambiental e contagiosa, sendo a primeira causada por microrganismos presentes no ambiente, como a Escherichia coli e a Klebisiella sp. A mastite contagiosa é causada por patógenos cujo habitat preferencial é o interior da glândula mamária e a superfície da pele dos tetos. Dessa forma, o principal momento de transmissão ocorre durante a ordenha dos animais, através das mãos do ordenhador, panos e esponjas para secagem de tetos, quando utilizados para várias vacas, e teteiras. Os principais patógenos causadores da mastite contagiosa são o Staphylococcus aureus, Streptococcus agalactiae e Corynebacterium bovis. As mastites subclínicas geralmente são do tipo contagioso e, nos rebanhos brasileiros, são as que causam maior prejuízo à exploração leiteira (FONSECA; SANTOS, 2000).

Dentre os métodos recomendados para o diagnóstico de mastite, pode se indicar o teste da caneca de fundo telado, o California Mastitis Test (CMT) e a Contagem de Células Somáticas (CCS) (FONSECA; SANTOS, 2000). Segundo RIBEIRO et al. (2003) o CMT é um dos testes mais utilizados para o diagnóstico da mastite subclínica, sendo um indicador indireto da contagem de células somáticas 
no leite. A CCS do leite de animais individuais ou de tanque é uma ferramenta valiosa na avaliação do nível de mastite subclínica no rebanho, na estimativa das perdas quantitativas e qualitativas de produção de leite e derivados, como indicativo de qualidade do leite produzido na propriedade e para estabelecer medidas de prevenção e controle da mastite (MULLER, 2002).

De acordo com Radostits et al. (2007), o exame microbiológico do leite é o método padrão para o diagnóstico da mastite bovina. Através da cultura do leite, é possível a identificação correta do agente etiológico, que por sua vez possibilita determinar prováveis fontes de infecção e, como consequência, a adoção de medidas específicas de controle (BELOTI et al., 1997).

O estudo da etiologia da mastite infecciosa merece atenção de vários pesquisadores, visando a elaboração de estratégias efetivas de controle, uma vez que o conhecimento dos microrganismos predominantes na etiologia dos casos de mastite em um rebanho permite a detecção de pontos críticos na propriedade leiteira que contribuem para a instalação e disseminação do processo infeccioso (COSTA et al., 2000). Muitos microrganismos podem causar a mastite e WATTS (1988) relata um total de 137 agentes etiológicos associados à infecção da glândula mamária em bovinos.

Estudando a mastite subclínica em rebanhos leiteiros no norte do Paraná, BELOTI et al. (1997), examinaram 295 quartos mamários positivos no CMT, sendo que 223 (75,59\%) amostras de leite, obteve-se crescimento bacteriano, e isolaram os seguintes microrganismos em cultura pura ou em associação, nas seguintes proporções: Streptococcus spp. - 21,69\%; Corynebacterium bovis - 18,98\%; Staphylococcus aureus - 17,97\%; Staphylococcus coagulase negativa - 12,54\%; Staphylococcus aureus e Streptococcus spp. - 1,01\%; Escherichia coli-0,67\%; Corynebacterium bovis e Streptococcus spp. 0,67\%; Pseudomonas aeruginosa - 0,33\%; Escherichia coli e Streptococcus spp. - 0,33\%;
Staphylococcus aureus e Staphylococcus coagulase negativa 0,33\%; Arcanobacterium pyogenes e Staphylococcus coagulase negativa - 0,33\%; Escherichia coli e Staphylococcus coagulase negativa - 0,33\%; Staphylococcus aureus e Escherichia coli-0,33\%.

Considerando estas informações, este estudo teve como objetivo verificar a prevalência e a etiologia da mastite clínica e subclínica no município de Nova Tebas, Estado do Paraná.

\section{Material e Métodos}

O município de Nova Tebas, PR, localizase a $650 \mathrm{~m}$ de altitude, na latitude $24^{\circ} 26^{\prime} 17^{\prime \prime}$ Sul e longitude 51 $56^{\prime} 43^{\prime}$ 'W. Apresenta clima subtropical úmido mesotérmico, com temperatura média anual de $20^{\circ} \mathrm{C}$ (PARANÁ, 2009) e solos litólicos, com relevo acidentado e declividade acentuada em vários pontos. Está localizado no Vale do Ivaí na região central do Estado do Paraná, possui cerca de $544,187 \mathrm{Km}^{2}$ de extensão. A pecuária conta com um rebanho bovino de 63.368 mil cabeças, 565 estabelecimentos produtores de leite, 8.300 vacas ordenhadas/dia (BRASIL, 2006), produção média de 30.000 mil litros/dia. A região do Vale do Ivaí tem no leite a terceira economia do setor agropecuário, representando em $40 \%$ das propriedades rurais $100 \%$ da renda familiar (HOLZMANN, 2008). Caracteriza-se por uma atividade predominantemente familiar e de subsistência, o que demonstra a necessidade de implantação de programas de conscientização e controle de práticas de higiene e processamento do leite.

O presente trabalho foi realizado em 17 propriedades no município de Nova Tebas, Centro Oeste do Estado do Paraná, no período de abril a junho de 2007. As propriedades foram classificadas quanto à produção de litros/vaca/dia, sendo assim denominadas de Sistema I, II e III segundo Koehler (2000).

As propriedades foram sorteadas aleatoriamente 
pelo programa Windows Microsoft Excel. As visitas nas propriedades foram feitas na primeira ordenha do dia. Antes da ordenha realizava-se o pré-dipping, lavava-se os tetos, desprezava-se os primeiros jatos em uma caneca de fundo telado, realizava-se a desinfecção com solução de hipoclorito de sódio e secagem com papel toalha descartável. A seguir foram realizados o CMT para detecção de mastite subclínica. Nos quartos mamários que apresentavam reações positivas ao teste, foram colhidas duas amostras de leite em tubo de ensaio estéril com tampa de rosca, uma para realização do CCS e outra para análise microbiológica.

As amostras para CCS foram acondicionadas em frascos de polietileno, com tampa de rosca e capacidade de $50 \mathrm{~mL}$ contendo duas pastilhas do conservante bronopol (2-bromo-2nitropropano-1, 3-diol), etiquetadas e encaminhada para o Laboratório do Programa de Análise de Leite da Associação Paranaense de Criadores de Bovinos da Raça Holandesa (APCBRH) em Curitiba, Estado do Paraná, utilizando o aparelho Somacount 500 (Bentley Instruments ${ }^{\circledR}$.

As amostras de leite para análise microbiológica foram acondicionadas em tubo de ensaio estéril com tampa de rosca, etiquetadas e encaminhadas em caixa isotérmica, mantida em refrigeração durante o transporte para o Laboratório de Doenças Infecciosas do Hospital Veterinário da Unipar em Umuarama, Estado do Paraná.

No laboratório, as amostras de leite foram semeadas em placas de ágar base, acrescido de 5\% de sangue ovino desfibrinado, e ágar MacConkey, sendo incubadas a $37^{\circ} \mathrm{C}$. O crescimento bacteriano foi verificado às 24, 48 e 72 horas. Cada colônia foi avaliada quanto às características macroscópicas (coloração ou pigmentação, presença ou ausência de hemólise, aspecto e tamanho da colônia), características microscópicas pela técnica de coloração de Gram e provas bioquímicas.

A associação entre o CMT, sistema de produção e os microrganismos isolados, comparados dois a dois, foi verificada pelo teste de $\chi^{2}$ no software
EpiInfo versão 3.5 (Centers for Disease Control, Atlanta). A influência do microrganismo sobre os escores de CMT e sobre a CCS foram comparados pelo teste de Kruskall-Wallis, utilizando-se o software BioEstat 5.0 (Instituto Mamirauã, Belém). Valores de P menores que 0,05 foram considerados significativos.

\section{Resultados e Discussão}

De 17 propriedades foram avaliadas 336 vacas em lactação, totalizando 1324 quartos mamários, sendo $1120(84,6 \%)$ negativos ao CMT e 204 $(15,4 \%)$ positivos.

Beloti et al. (1997) estudando 503 vacas, oriundas de propriedades produtoras de leite $\mathrm{B}$ da região norte do Paraná citam uma ocorrência superior, com 29,82\% de quartos mamários positivos no CMT. Pardo et al. (1999) e Ribeiro Júnior et al. (2008), também encontraram índices de CMT positivos superiores ao deste trabalho, $43,06 \%$ e $53,4 \%$, respectivamente.

Não houve diferença entre os sistemas de produção com relação a proporção de quartos CMT positivos. Entretanto, considerando os resultados +++ , houve maior frequência nos sistemas II e III (7,4\% e 5,4\%, respectivamente), ou seja, naquelas propriedades de maior produção e, na maioria das vezes, com maior tecnificação, provavelmente devido a falhas de manejo. Por outro lado, o sistema I, onde houve 3,4\% de CMT +++ , apresenta maior rusticidade dos animais, presença de bezerro ao pé e ordenha manual. Deve-se salientar ainda que animais desta categoria apresentam uma menor produção de leite e consequentemente menor prevalência de mastite. Segundo Combellas (1998) as vacas ordenhadas sem bezerro têm três a quatro vezes mais chances de apresentar mastite subclínica do que as que amamentam.

Amostras dos 204 (15,4\%) quartos mamários positivos foram encaminhadas para exame microbiológico, e $155 \quad(75,9 \%)$ apresentaram crescimento bacteriano. Dentre os patógenos 
isolados, houve maior frequência dos Staphylococcus coagulase negativa $(32,9 \%)$, seguidos de Streptococcus sp. (31,6\%), Corynebacterium bovis (12,3\%), Staphylococcus coagulase positiva $(12,3 \%)$, bacilo Gram negativo (BGN) $(7,7 \%)$, Corynebacterium sp. (1,9\%) e Candida sp. (1,2\%).

Resultados deste trabalho foram inferiores aos encontrados por Pardo et al. (1999) em levantamento dos agentes etiológicos da mastite bovina na região de Arapongas (PR), que constatou 82 isolados de Staphylococcus coagulase negativa (86,32\%). Porém a prevalência de Staphylococcus coagulase positiva e Corynebacterium bovis foi bastante semelhante, sendo $13,68 \%$ e $15,82 \%$, respectivamente.

Filippsen et al. (1999), em estudo da prevalência da mastite bovina causada por Prototheca zopfii em rebanhos leiteiros na região Norte do Paraná, constataram maior frequência de Corynebacterium bovis (218 amostras; 33,03\%), seguido por Staphylococcus coagulase negativa (211 amostras; $31,97 \%$ ), semelhante ao encontrado neste trabalho.

Em um estudo de 88 vacas primíparas, oriundas de rebanhos leiteiros do Norte do Estado do Paraná e Sudoeste de São Paulo, isolou-se Staphylococcus coagulase negativa em 316 amostras (69,14\%), Corynebacterium bovis em 56 amostras (12,25\%), Streptococcus sp. em 41 amostras (8,97\%) e Staphylococcus coagulase positiva em 38 amostras (8,31\%) (LAFFRANCHI et al., 2001).

Benites et al. (2001), estudando 140 quartos mamários no Estado de São Paulo, verificaram a alta ocorrência de Staphylococcus coagulase negativa $76(54,29 \%)$, enquanto que o isolamento de Staphylococcus coagulase positiva foi verificado em $9(6,43 \%)$ amostras.

Ribeiro Junior et al. (2008) obtiveram maior prevalência de Staphylococcus epidermidis (50\%) e Staphylococcus aureus (20\%), em estudo de métodos de diagnósticos indireto de mastite subclínica na Bahia.

De uma maneira geral, os isolamentos realizados apresentaram semelhança com aqueles encontrados na etiologia da mastite bovina em diferentes regiões do Brasil. As variações de prevalência encontradas devem-se provavelmente as diferentes técnicas de manejo, aplicados nos rebanhos estudados, bem como as medidas profiláticas desenvolvidas.

Nos resultados do CMT,+++ e +++ foram identificados como mais prevalente o Streptococcus sp., Staphylococcus CN e Streptococcus sp., respectivamente. Pode-se observar que nos quartos mamários que apresentaram resultado de CMT +++ houve uma maior frequência de crescimento bacteriano, em relação aos resultados do CMT $++\mathrm{e}+$, demonstrando associação entre o teste de CMT e a análise microbiológica (Tabela 1). De todos os microrganismos isolados, os contagiosos apresentaram maior frequência quando comparados a reação positiva pelo CMT. Estes resultados são semelhantes aos descritos por Oliveira, Melo e Azevedo (2009), em Sergipe, que justificaram a presença mais acentuada de microrganismos contagiosos em sistemas de produção precários em higiene. 
Tabela 1. Frequência absoluta (n) e relativa (\%) de microrganismos em função do resultado do California Mastit Test (CMT). Nova Tebas, 2007.

\begin{tabular}{lllll}
\hline \multirow{2}{*}{ Microrganismos } & \multicolumn{4}{c}{ CMT } \\
\cline { 2 - 5 } & + & ++ & +++ & TOTAL \\
\hline BGN & $6(14,6)$ & $3(5,8)$ & $3(4,8)$ & $12(7,7)$ \\
Candida albicans & $0(0,0)$ & $0(0,0)$ & $1(1,6)$ & $1(1,6)$ \\
Candida sp. & $0(0,0)$ & $0(0,0)$ & $1(1,6)$ & $1(1,6)$ \\
Corynebacterium bovis & $8(19,5)$ & $11(21,2)$ & $0(0,0)$ & $19(12,3)$ \\
Corynebacterium sp. & $0(0,0)$ & $2(3,8)$ & $1(1,6)$ & $3(1,9)$ \\
Staphylococcus CN. & $9(22,0)$ & $18(34,6)$ & $24(38,7)$ & $51(32,9)$ \\
Staphylococcus CP. & $5(12,2)$ & $8(15,4)$ & $6(9,7)$ & $19(12,3)$ \\
Streptococcus & $13(31,7)$ & $10(19,2)$ & $26(41,9)$ & $49(31,6)$ \\
TOTAL & $41(26,5)$ & $52(33,5)$ & $62(40,0)$ & $155(100,0)$ \\
\hline
\end{tabular}

Estatística: $\chi^{2}=28,51 ; p=0,0121$.

Fonte: Elaboração dos autores.

Os resultados da tabela 2 demonstram que com o aumento da produtividade e tecnificação nos sistemas de produção de leite, há um aumento significativo da prevalência de mastites, o que pode ser decorrente de falhas no manejo de ordenha e de higienização dos equipamentos. Observou-se uma diferença significativa entre a análise microbiológica e os sistemas de produção de leite $(\mathrm{p}=0,0002)$.

Tabela 2. Frequência absoluta (n) e relativa (\%) de microrganismos segundo o sistema de produção de leite. Nova Tebas, 2007.

\begin{tabular}{lllll}
\hline \multicolumn{1}{c}{ Microrganismos } & \multicolumn{3}{c}{ Classificação } & \\
\cline { 2 - 5 } & Sistema I & Sistema II & Sistema III & TOTAL \\
\hline BGN & $2(22,2)$ & $5(7,9)$ & $5(6,0)$ & $12(7,7)$ \\
Candida albicans & $0(0,0)$ & $0(0,0)$ & $1(1,2)$ & $1(0,6)$ \\
Candida sp. & $0(0,0)$ & $1(1,6)$ & $0(0,0)$ & $1(1,6)$ \\
Corynebacterium bovis & $1(11,1)$ & $5(7,9)$ & $13(15,7)$ & $19(12,3)$ \\
Corynebacterium sp. & $2(22,2)$ & $1(1,6)$ & $0(0,0)$ & $3(1,9)$ \\
Staphylococcus CN. & $3(33,3)$ & $28(44,4)$ & $20(24,1)$ & $51(32,9)$ \\
Staphylococcus CP. & $0(0,0)$ & $10(15,98)$ & $9(10,8)$ & $19(12,3)$ \\
Streptococcus & $1(11,1)$ & $13(20,6)$ & $35(42,2)$ & $49(31,6)$ \\
\hline TOTAL & $9(5,8)$ & $63(40,6)$ & $83(53,5)$ & $155(100,0)$ \\
\hline
\end{tabular}

Estatística: $\chi^{2}=40,56 ; p=0,0002$.

Fonte: Elaboração dos autores.

Um estudo da etiologia das mastites bovinas nas sete principais bacias leiteiras do Estado de São Paulo demonstrou maior ocorrência de microrganismos do gênero Corynebacterium sp. nas propriedades de leite tipo C, Streptococcus sp. em propriedades de leite tipo B, e Staphylococcus sp. nas propriedades de leite tipo A (COSTA et al.,
2000), confirmando que o sistema de produção está diretamente relacionado ao manejo adotado pelas propriedades.

Nos resultados de CMT e CCS obteve-se diferença significativa quando comparado o Corynebacterium bovis e Staphylococcus coagulase negativa; e Corynebacterium bovis e Streptococcus 
sp. (Tabela 3). Desta forma podemos destacar que os microrganismos causadores das mastites contagiosas mostraram-se mais antigênicos quando comparados com os patógenos das mastites ambientais, demonstrando que os testes de CMT e CCS utilizados no diagnóstico refletem a indução da resposta imune desencadeada por cada um destes microrganismos.

Tabela 3. Valores de CMT e CCS segundo os microrganismos, Nova Tebas, 2007.

\begin{tabular}{lllllll}
\hline \multirow{2}{*}{ Microrganismos } & CMT & \multicolumn{5}{l}{ CCS X 1.000 } \\
\cline { 2 - 7 } & Mediana & P25 & P75 & Mediana & P25 & P75 \\
\hline BGN & $1,00^{\mathrm{ab}}$ & 1,00 & 2,00 & $926,00^{\mathrm{ab}}$ & 283,00 & 1526,00 \\
C. bovis & $1,00^{\mathrm{a}}$ & 1,00 & 2,00 & $577,00^{\mathrm{a}}$ & 343,00 & 1248,00 \\
Staphylococcus C.N. & $2,00^{\mathrm{b}}$ & 2,00 & 3,00 & $1226^{\mathrm{b}}$ & 688,00 & 2232,00 \\
Staphylococcus C.P. & $2,00^{\mathrm{ab}}$ & 2,00 & 3,00 & $1349,00^{\mathrm{ab}}$ & 701,00 & 1750,00 \\
Streptococcus sp. & $3,00^{\mathrm{abc}}$ & 2,00 & 3,00 & $1510,00^{\mathrm{abc}}$ & 769,00 & 2833,00 \\
\hline
\end{tabular}

Estatística: valores de mediana seguidos de letras minúsculas diferentes indicam diferenças significativas pelo teste de KruskallWallis.

Fonte: Elaboração dos autores.

Carneiro, Domingues e Vaz (2009) descrevem que, em linhagens de Staphylococcus aureus isolados de mastite bovina, observa-se que a presença da cápsula polissacarídica (tipos 5 e 8) evita a deposição dos componentes do complemento e sua consequente ação opsonizadora. Estes autores comentam ainda a relação entre a lactoferrina e os agentes etiológicos de mastite na glândula mamária bovina, destacando a suscetibilidade do Staphylococcus aureus a ação bactericida desta enzima. Esses dados sugerem que diferentes espécies de microrganismos podem determinar diferentes respostas imunes da glândula mamária.

Elias et al. (2005) confirmam que o microrganismo interfere no aumento das células somáticas ao estudar as características fisicoquímicas e contagem de células somáticas de leite proveniente de vacas naturalmente infectadas por Streptococcus sp.

Entretanto o Corynebacterium sp. mostrase menos antigênico, quando avaliada a CCS de animais infectados por este microrganismo. Victória et al. (2005), ao relacionar a infecção deste patógeno com a CCS, verificaram que apesar de discretas, as alterações na quantidade de células somáticas foram significativas e permitem refletir sobre a importância de patógenos considerados de menor relevância nas infecções da glândula mamária, como o Corynebacterium bovis, uma vez que este microrganismo está geralmente associado a outros patógenos de maior importância nas mastites. Zafalon et al. (2005) obtiveram resultados semelhantes ao avaliar animais infectados com este mesmo microrganismo.

De acordo com a Instrução Normativa $n^{\circ}$ 51, de 18 de setembro de 2002, do Ministério da Agricultura Pecuária e Abastecimento (MAPA), fica estabelecido um padrão para o leite cru refrigerado de limites máximo de contagem de células somáticas de 750.000 cels $/ \mathrm{mL}$, baixando para um máximo de 400.000 cels $/ \mathrm{mL}$ em 2011, nos Estados do Sul, Sudeste e Centro-Oeste (BRASIL, 2002). Em relação aos padrões estabelecidos pelo MAPA, há uma necessidade de melhorar a qualidade do leite produzido para cumprir a legislação em vigor.

Os resultados encontrados neste trabalho mostram que a prevalência de mastite no município de Nova Tebas é compatível aos encontrados nas demais regiões do Brasil, bem como os agentes etiológicos mais frequentes. Concluindo que a 
prevalência de mastite subclínica encontrada no rebanho leiteiro de Nova Tebas foi de 15,4\%, sendo o Staphylococcus coagulase negativa, Streptococcus e Corynebacterium bovis os microrganismos mais frequentes para a região estudada.

\section{Comitê de ética}

O presente trabalho foi aprovado pelo Comitê de Ética em Pesquisa e Experimentação Animal, protocolado sob número11167/2007 em reunião realizada no dia 23 de novembro de 2006.

\section{Referências}

BELOTI, V.; MULLER, E. E.; FREITAS, J. C.; METIFOGO, E. Estudo da mastite subclínica em rebanhos leiteiros no norte do Paraná. Semina: Ciências Agrárias, Londrina, v. 18, n. 1, p. 45-53, mar. 1997.

BENITES, N. R.; GUERRA, J. L.; MELVILLE, P. A.; COSTA, E. O. Etiologia e histopatologia de mastites bovinas de ocorrência espontânea. Revista Napgama, São Paulo, v. 4, n. 1, p. 3-8, 2001.

BLOOD, D. C.; RADOSTITS, O. M. Clínica veterinária. 7. ed. Rio de Janeiro: Guanabara Koogan, 1991. 1770 p.

BRASIL. Instituto Brasileiro de Geografia e Estatística Censo Agropecuário, 2006. Brasília: IBGE, 2006. Acesso em: 20 jun. 2008.

Ministério da Agricultura Pecuária e Abastecimento. Instrução Normativa $n^{\circ}$ 51. Brasília, DF: MAPA, 2002. 48 p.

CARNEIRO, D. M. V. F.; DOMINGUES, P. F.; VAZ, A. K. Imunidade inata da glândula mamária bovina: resposta à infecção. Ciência Rural, Santa Maria, v. 39, n. 6, 2009. Disponível em: <http://www.scielo. br/pdf/ cr/2009nahead/a227cr862.pdf>. Acesso em: 15 jul.2009.

COMBELLAS, L. J. Alimentación de la vaca de doble propósito y de sus crías. Valencia: Fundación Inlaca, 1998. $195 \mathrm{p}$.

COSTA, E. O.; GARINO JUNIOR, F.; MELVILLE, P. A.; RIBEIRO, A. R.; SILVA, J. A. B.; WATANABE, E. T.; VALLE, C. R. Estudo da etiologia das mastites bovinas nas sete principais bacias leiteiras do estado de São Paulo. Revista Napgama, São Paulo, v. 3, n. 4, p. 6-13, 2000.

ELIAS, A. O.; VICTORIA, C.; DA SILVA, A. V.; LANGONI, H. Características físico-químicas e contagem de células somáticas de leite proveniente de vacas naturalmente infectadas por Streptococcus spp. Arquivos de Ciências Veterinárias e Zoologia da UNIPAR. Umuarama, v. 8, n. 2, p. 165-170, 2005.

FAGAN, E. P. Fatores ambientais e de manejo sobre a composição química, microbiológica e toxicológica do leite produzido em duas granjas produtoras de leite tipo "A" no Estado do Paraná. 2006. Tese (Doutorado em Zootecnia) - Programa de Pós-Graduação em Zootecnia. Universidade Estadual de Maringá, Maringá.

FILIPPSEN, L. F.; MOREIRA, F. B.; SAKASHITA, A. T.; BITTENCOURT, D. R. Prevalência da mastite bovina causada por Prototheca zopfii em rebanhos leiteiros, na região norte do Paraná. Ciência Rural, Santa Maria, v. 29, n. 1, p. 87-89, 1999.

FONSECA, L. F. L.; SANTOS, M. V. Qualidade do leite e controle de mastite. São Paulo: Lemos Editorial, 2000. $175 \mathrm{p}$.

HOLZMANN, V. M. M. Organização da assistência técnica na região do Vale do Ivaí, Paraná Centro, através da implantação do projeto vale mais leite. In: CONGRESSO BRASILEIRO DE ASSISTÊNCIA TÉCNICA E EXTENSÃO RURAL - CONBATER, 4., 2008, Londrina. Anais... Londrina: Combater, maio 2008. p. 613-621.

KOEHLER, J. C. Caracterização da bovinocultura de leite no Estado do Paraná. Curitiba: Seab, 2000. Disponível em: $<$ http://www.pr.gov.br/seab/deral/cultura3.pdf $>$. Acesso em: 05 jun. 2007.

LAFFRANCHI, A.; MULLER, E. E.; FREITAS, J. C.; PRETTO-GIORDANO, L. G.; DIAS, J. A.; SALVADOR, R. Etiologia das infecções intramamárias em vacas primíparas ao longo dos primeiros quatro meses de lactação. Ciência Rural, Santa Maria, v. 31, n. 6, p. 1027-1032, 2001.

LANGONI, H. Complexidade etiológica na mastite bovina. In: ENCONTRO DE PESQUISADORES EM MASTITES FMVZ/UNESP, 3., 1999, Botucatu. Anais... Botucatu: UNESP, 1999. p. 3-18.

MULLER, E. E. Qualidade do leite, células somáticas e prevenção da mastite. In: SUL-LEITE: SIMPÓSIO SOBRE SUSTENTABILIDADE DA PECUÁRIA LEITEIRA NA REGIÃO SUL DO BRASIL, 2., 2002, Maringá. Anais... Maringá: UEM, 2002. p. 206-217. Disponível em: <http://www.nupel.uem.br/ qualidadeleitem.pdf $>$. Acesso em: 20 nov. 2008.

OLIVEIRA, A. A.; MELO, C. B.; AZEVEDO, H. C. Diagnóstico e determinação microbiológica da mastite em rebanhos bovinos leiteiros nos tabuleiros costeiros de Sergipe. Ciência Animal Brasileira, Goiânia, v. 10, n. 1, p. 226-230, jan./mar. 2009. 
PARANÁ. Instituto Paranaense de Desenvolvimento Econômico e Social. Perfil do Município de Nova Tebas. Curitiba: Ipardes, 2009. Disponível em: $<$ http:// www.ipardes.gov.br/perfil_municipal/MontaPerfil. php? Municipio $=85250 \& b t O k=0 k>$. Acesso em: 20 jun. 2008.

PARDO, R. B.; CHAVES NETO, A. F.; FERNANDES, G. D.; DUARTE, D. D. S.; FERNANDES, A. A.; YOKOSAWA, S. Y.; MENCK, R. C.; GODOY, C. A. de; FARINAZZO, A. M.; PANÍCIO, E. Levantamento dos agentes etiológicos da mastite bovina na região de Arapongas (PR). UNOPAR Cientifica: Ciências Biológicas e da Saúde, Londrina, v. 1, n. 1, p. 25-30, out. 1999.

RADOSTITS, O. M.; GAY, C. C.; HINCHCLIFF K, W.; CONSTABLE, P. D. Veterinary medicine: a textbook of the diseases of cattle, horses, sheep, pigs and goats. 10 . ed. Philadelphia: Saunders Elsevier, 2007. 2156 p.

RIBEIRO JÚNIOR, E.; SILVA, M. H.; VIEGAS, S. A. de A.; RAMALHO, E. J.; RIBEIRO, M. D.; OLIVEIRA, F. C. S. Califórnia mastitis test (CMT) e whiteside como métodos de diagnóstico indireto da mastite subclínica. Revista Brasileira de Saúde Produção Animal, Salvador, v. 9, n. 4, p. 680-686, out./dez. 2008. Disponível em: $<$ http://www.rbspa.ufba.br>. Acesso em: 15 jun. 2009.
RIBEIRO, M. E. R.; PETRINI, L. A.; AITA, M. F.; BALBINOTTI, M.; STUMPF JUNIOR, W.; GOMES, J. F.; SCHRAMM, R. C.; MARTINS, P. R.; BARBOSA, R. S. Relação entre mastite clínica, subclínica infecciosa e não infecciosa em unidades de produção leiteiras na região sul do Rio Grande do Sul. Revista Brasileira Agrociência, Jaboticabal, v. 9, n. 3, p. 287-290, jul./set. 2003. Disponível em: <http://www.ufpel.che.br/faem/ agrociencia/v9n3/artigo18.pdf>. Acesso em: 23 nov. 2008.

VICTÓRIA, C.; DA SILVA, A. V.; ELIAS, A. O.; LANGONI, H. Corynebacterium bovis e os padrões de contagem de células somáticas no Brasil. Arquivos de Ciências Veterinárias e Zoologia da UNIPAR, v. 8, n. 2, p. 161-164, 2005.

WATTS, J. L. Etiological agents of bovine mastitis. Veterinary Microbiology, Barcelona, v. 16, n. 1, p. 41-66, 1988

ZAFALON, L. F.; NADER FILHO, A.; AMARAL, L. A.; OLIVEIRA, J. V.; RESENDE, F. D. Alterações da composição e da produção de leite oriundo de quartos mamários de vacas com e sem mastite subclínica de acordo com o estágio e o número de lactações. Arquivos do Instituto Bioógicol, São Paulo, v. 72, n. 4, p. 419-426, out./dez. 2005. 
